\title{
Battaniye İşletmesinde Maruz Kalınan Gürültünün İş Sağlığı ve Güvenliği Açısından Değerlendirilmesi
}

\author{
Murat KODALOĞLU' ${ }^{1}$ Kamil DELİKANLI ${ }^{2}$ \\ ${ }^{1}$ Isparta Uygulamalı Bilimler Üniversitesi, Teknik Bilimler MYO, İs Sağlı̆̆ı ve Güvenliği Programı, Isparta, Türkiye \\ ${ }^{2}$ Süleyman Demirel Üniversitesi, Mühendislik Fakültesi, Makina Mühendisliği Bölümü, Isparta, Türkiye
}

(Alınış / Received: 3.11.2020, Kabul / Accepted: 3.3.2021)

\section{Anahtar Kelimeler}

Gürültü,

Örme,

Şardon,

Dozimetre,

Maruziyet.

\begin{abstract}
Özet: Gürültü, sanayileşmenin etkin olarak yaşandığı ülkelerde işçi sağlığını ve hayat kalitesine etki eden önemli bir sorundur. İşçiler, çalışma hayatının değişik ortamlarında gürültülü alanlarda bulunmaktadır. Gürültüden zarar gören kesimi, yüksek oranda gürültünün meydana geldiği iş yerinde çalışan işçiler oluşturmaktadır. Gürültünün; işçi sağlğı̆nı fizyolojik ve psikolojik olarak negatif yönde etkilediği bilinmektedir. Gürültü, işçilerin yaptıkları faaliyetlerden yakınmalarına neden olması, işçilerin verimini negatif yönde etkilemesi sonucunda verim kaybına neden olmaktadır. Fabrikalarda değişen gürültülü çalışma ortamlarda bulunan işçilerin gürültü maruziyet durumlarını incelemeyi amaçlanmıştır. Battaniye işletmesinin örme ve şardon bölümlerinin gürültü düzeyi ölçümleri yapılarak belirlenmiştir. Örme ve şardon makinalarının ortama yaydıkları gürültü ses basınç düzeyi değerleri ölçülmüştür. Ölçüm sırasında; iş analizinde tespit edilen nominal gün şartlarının dışına çıkılmadığı gözlenmiştir. Görevler belirlenen süreler içinde gerçekleştirilmiştir ve tüm gürültü kaynakları tespit edilen sürelerde çalışılmıştır.
\end{abstract}

\section{Evaluation Of Noise Level Exposed In The Blanket Mill In Terms Of Occupational Health And Safety}

\section{Keywords}

Noise ,

Knitting,

Raising Machine,

Dosimetry,

Exposure.

\begin{abstract}
Noise is an important problem that influences human health and life quality in the countries where industrialization is intense. People may stay in the noisy areas during their life period. However the workers in industrial establishments are the most effected ones by the noise where high levels of noise occur. The effects of noise on people are very diverse; It is accepted by all countries that it negatively affects human health in terms of physiological and psychological aspects. It should be remembered that noise results with workers complaining about their work, affecting their performance as well as loss of workforce. Within the scope of this study, which aims to examine the noise effects of people working in different noisy environments at the factories, the noise levels of the knitting and raising sections of the blanket mill were determined. The spreading sound pressure level values of the knitting and raising machines were measured. During the measurement; it is observed that the nominal day conditions determined in the job analysis are not exceeded. Tasks were carried out within specified times, and all noise sources were studied within the determined times.
\end{abstract}




\section{Giriş}

Makinalaşma ile iş verimini negatif yönde etkileyen makine etkilerinden birisi gürültüdür. Gürültü, birden fazla iş ekipmanının bulunduğu ortam koşullarında, makinaları kullanan işçilere yüksek oranda zararlar vermektedir. Yüksek gürültü düzeyi, işçilerin sağlığını ve performanslarını negatif yönde etkilemektedir. Battaniye işletmesinde kullanılan örme ve şardon makinalarının oluşturduğu gürültünün işçi sağlığı üzerindeki negatif etkileri tespit makinaların ortama yaydı̆̆ı gürültü düzeyinin saptanması gereklidir. Battaniye işletmesinde gürültü düzeyi ölçümü yapılmış ve işçi üzerindeki etkileri incelenmiştir.

Ses bireye bağlı olarak değişmeyen ölçülebilir nesnel kavramdır. Gürültü öznel bir kavramdır. Gürültü "rahatsız edici ses" olarak tanımlanabilir. Sesin gürültü olarak kabul edilmesi bireylere bağlı olarak değişebilir[1]

İșitme duyusu zarar gören bir kișide, ișitme kaybı adı verilen, işitme kabiliyetinde zayıflama görülür. İşitme kaybı, geçici olabileceği gibi kalıcı da olabilir. İşitme kaybı kalıcı ya da geçici olması ve işitme kaybı derecesi; gürültünün seviyesine, gürültünün frekansına, çalışanın gürültünün maruziyetinde kaldığı süreye bağlıdır.[2]

Gürültünün maruziyet süresi, kişinin aralıksız gürültünün etkisinde kaldığı süreyi ve zaman zaman gürültünün etkisinde kaldığı yılları kapsar. Belirli düzeydekii sesin etkisinde bir zaman kalmak işitme kaybına sebep olur.[3]. Sanayileşmiş ülkelerde maruz kalınan gürültü sınır değerleri, bir günde veya bir haftada belirli bir düzeydeki gürültünün etkisinde kalınan en uzun süredir. Gürültünün frekansı, ortamda kalma süresi, gürültüye maruz kalan işçinin yaşı, fizyolojik ve psikolojik durumu, gürültünün bulunduğu ortamda zamana göre dağılımı gürültünün alıcı tarafından rahatsızlık olarak algılanmasında önemli olan etkenlerdendir[4]. Gürültünün birey üzerindeki negatif etkileri çoğunlukla fizyolojik ve psikolojik olmaktadır[5] .

Fizyolojik etkilerin en başında işitme kayıpları gelir. Gürültünün kulakta meydana getirdiği işitme etkilerini akustik travma, geçici ve kalıcı işitme kaybı olarak üç grupta toplamak mümkündür[6]. Gürültüye bağlı işitme kaybı gelişmiş toplumlarda yaygın görülen, yaşam kalitesini negatif yönde etkileyen sebeplerden biridir [7]. Fizyolojik sorunlar arasında kan basıncının artması, kalp atışlarının hızlanması, kas reflekslerinin oluşması, uyku bozuklukları sayılabilir. Saatlerce gürültünün etkisinde kalma; adrenalin, dolaşım stresi hormonlarının artması ile kan basıncında bozulmaya neden olabilir[8] . Gürültünün psikolojik etkileri sıkıntı, gerginlik, kızgınlık, konsantrasyon bozukluğu, algllama zorluğu şeklinde ortaya çıkmaktadır[5].

Gürültünün çalıșan sağlığı üzerindeki etkilerini azaltmak amacıyla çeşitli toplu ve kişisel koruyucu tedbirler alınmaktadır. Öncelikle gürültüye neden olan etkenlerin tespit edilmesi ve işçi sağlığına olan etkilerinin azaltılması gelmektedir. Bununla birlikte çoğu ülkede gürültünün etkilerini azaltmak için kanunlar çıkarılmıştır.

\section{Materyal ve Metot}

Deneysel çalışmalarda, battaniye fabrikasında kullanılan örme ve şardon tezgahlarında gürültü ölçümleri yapılmıştır.

Tablo 1. Bölümlerde yapılan işler ve maruziyet kaynakları

\begin{tabular}{|c|c|c|c|}
\hline Bölüm & $\begin{array}{c}\text { Yapılan } \\
\text { İşler }\end{array}$ & $\begin{array}{l}\text { Gürültü } \\
\text { çalışma } \\
\text { Alanları }\end{array}$ & $\begin{array}{c}\text { Gürültü } \\
\text { Seviyesinin } \\
\text { Değişimine } \\
\text { Sebep } \\
\text { Olabilecek } \\
\text { Durumlar }\end{array}$ \\
\hline $\begin{array}{c}\text { Örme } \\
\text { bölümü }\end{array}$ & $\begin{array}{c}\text { Battaniye } \\
\text { kumaşı } \\
\text { örme } \\
\text { işlemi ve } \\
\text { levent } \\
\text { sarma }\end{array}$ & $\begin{array}{c}\text { Örme } \\
\text { makinası } \\
\text { ve levent } \\
\text { sarma } \\
\text { makinası }\end{array}$ & $\begin{array}{c}\text { Çalışmakta olan } \\
\text { alet ve } \\
\text { ekipmanlardan } \\
\text { kaynaklı ses } \\
\text { gürültü } \\
\text { seviyesinde } \\
\text { değişime sebep } \\
\text { olmaktadır. }\end{array}$ \\
\hline $\begin{array}{l}\text { Şardon } \\
\text { Bölümü }\end{array}$ & $\begin{array}{l}\text { Battaniye } \\
\text { fırçalama } \\
\text { işlemi , } \\
\text { kesim } \\
\text { işlemi ve } \\
\text { sıcak baskı } \\
\text { işleri }\end{array}$ & $\begin{array}{c}\text { Şardon } \\
\text { makinası, } \\
\text { kesim } \\
\text { makinası, } \\
\text { sıcak baskı } \\
\text { makinası }\end{array}$ & $\begin{array}{c}\text { Çalışmakta olan } \\
\text { alet ve } \\
\text { ekipmanlardan } \\
\text { kaynaklı ses } \\
\text { gürültü } \\
\text { seviyesinde } \\
\text { değişime sebep } \\
\text { olmaktadır. }\end{array}$ \\
\hline
\end{tabular}




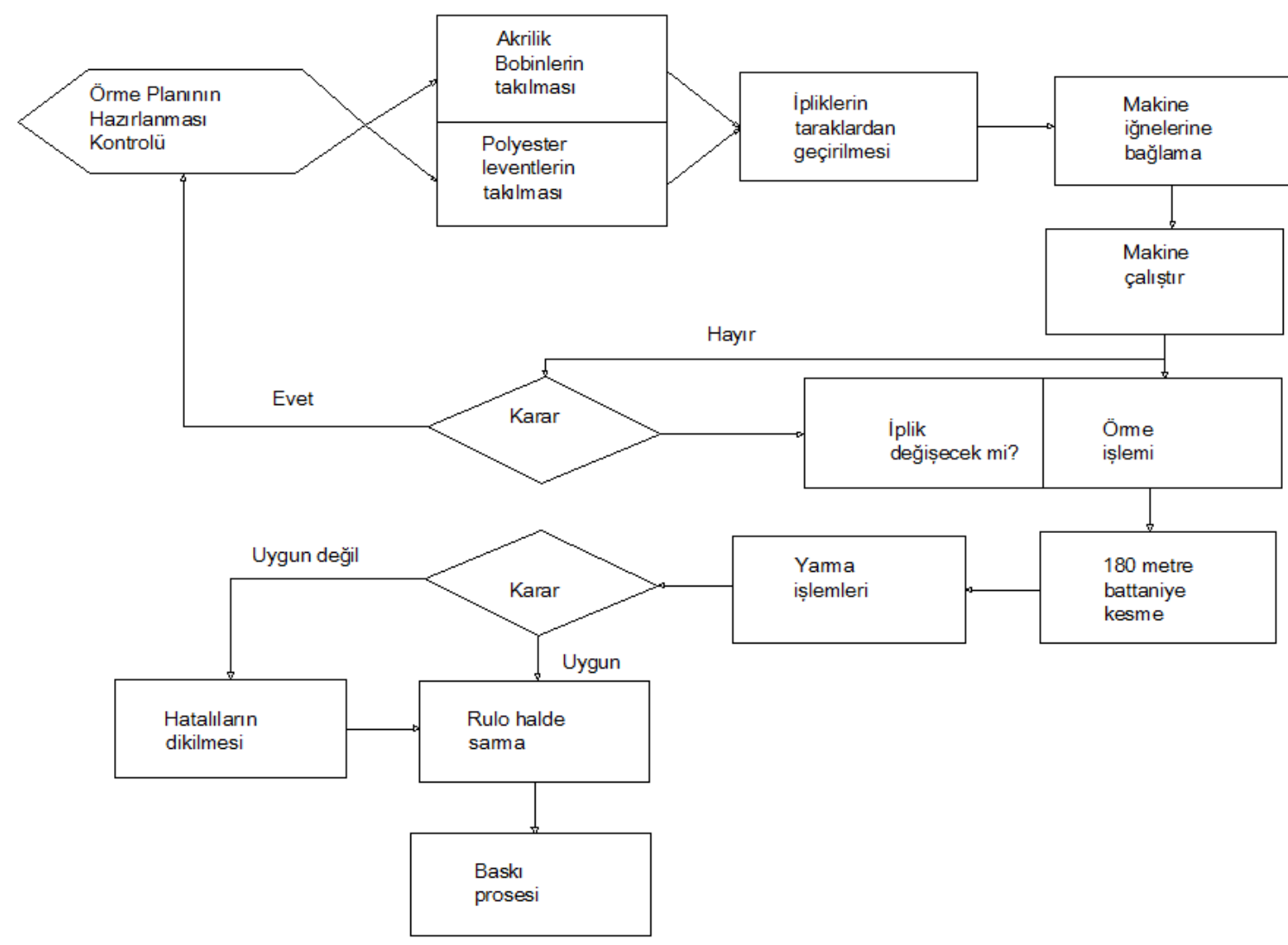

Şekil 1. Örme bölümü iș akış şeması

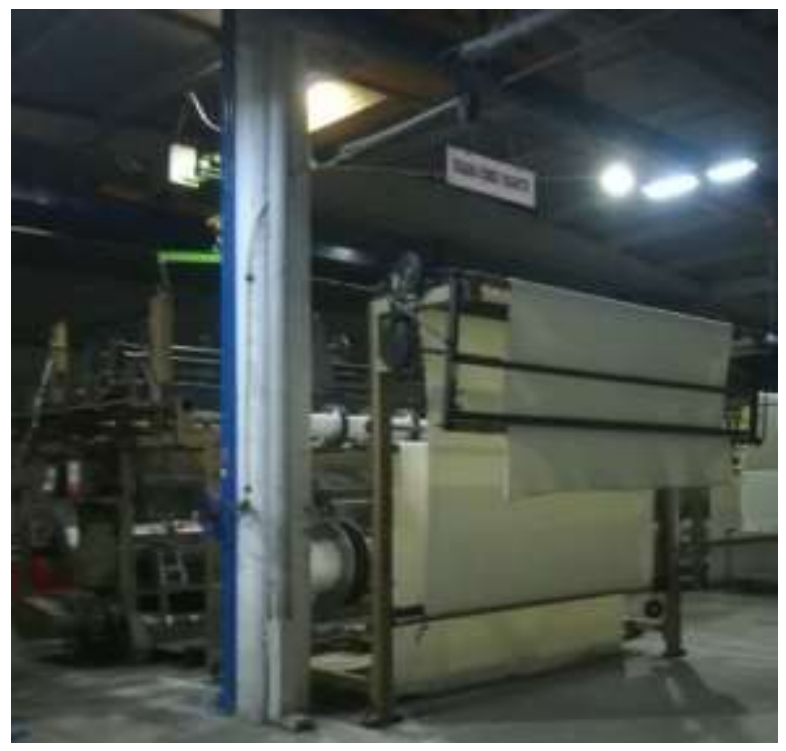

Şekil 2.(a) Örme makinası

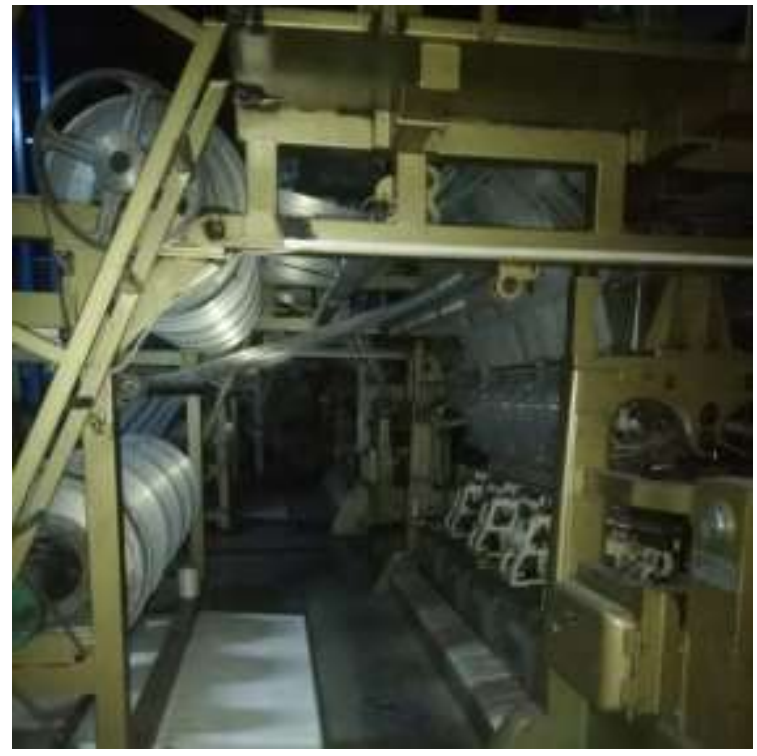

Şekil 2.(b)Örme makinası 


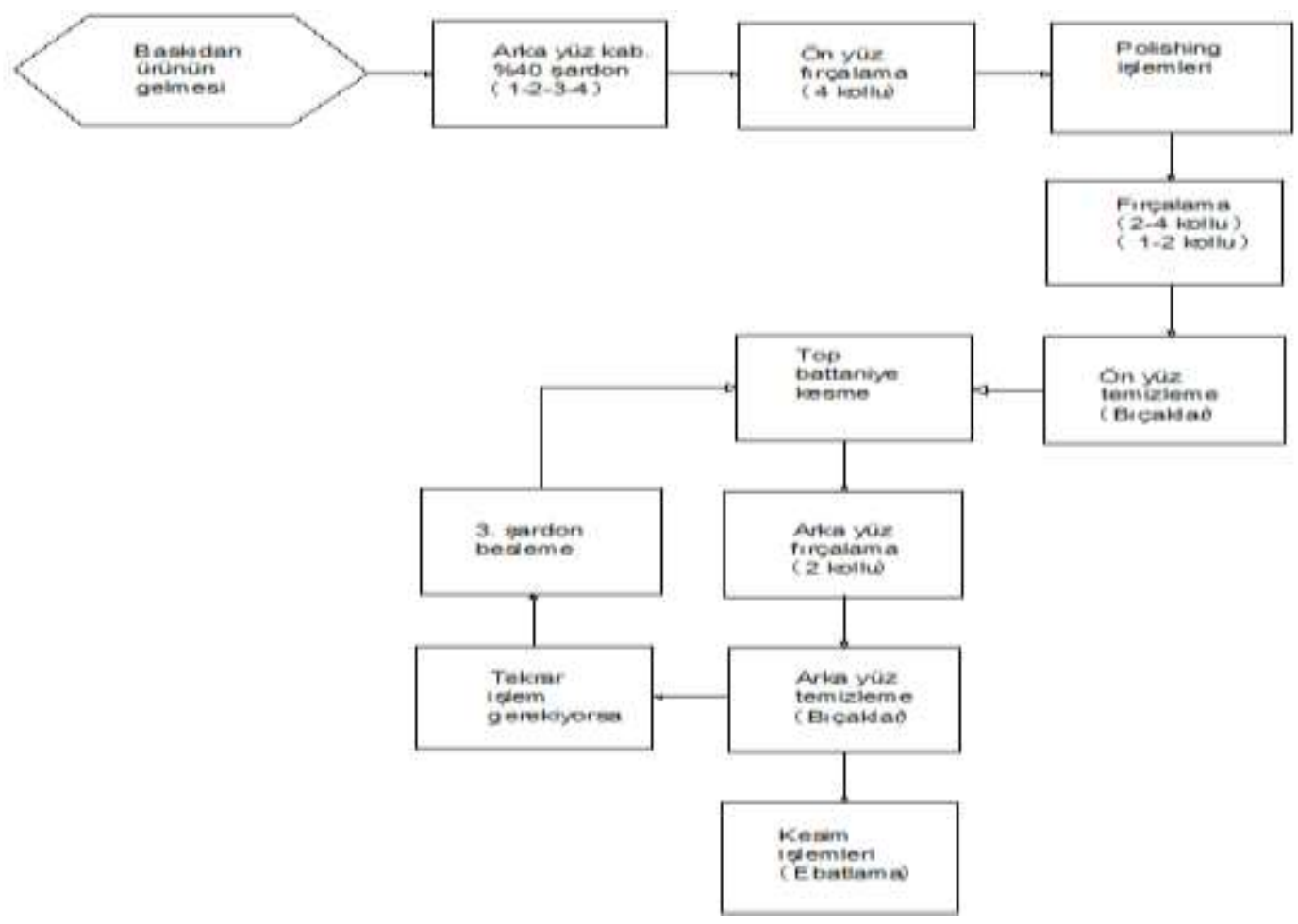

Şekil 3. Şardon bölümü iş akış șeması

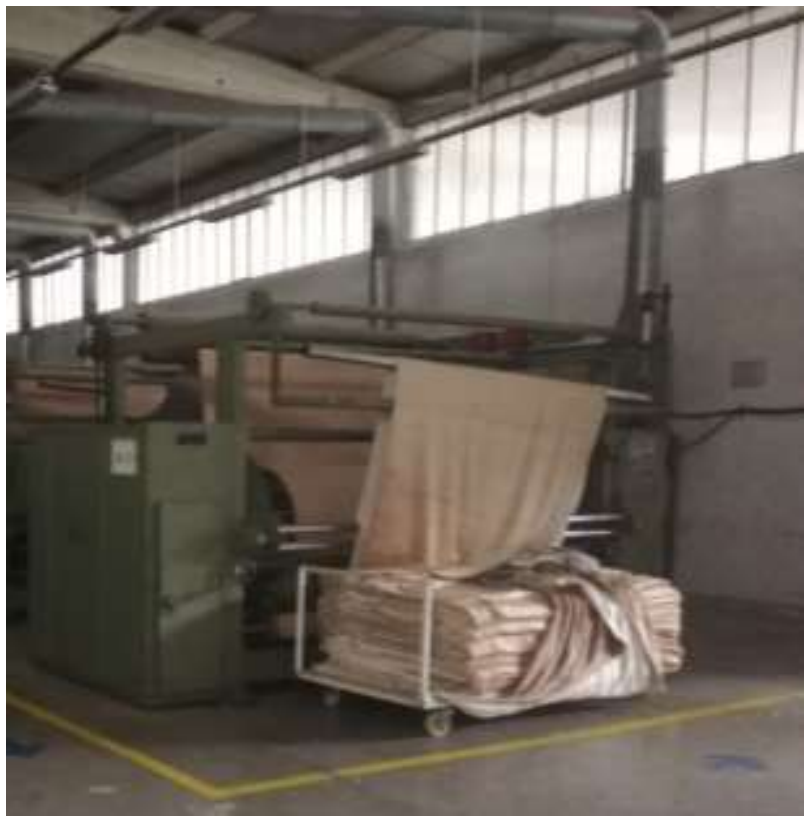

Şekil 4. Şardon makinası

\subsection{Materyal ve metot alt başlığı}

Tablo 2. Ölçüm sırasında çalışma şartları ve iş yeri faktörlerinin tanımlanması

\begin{tabular}{|c|c|c|c|c|c|c|}
\hline Bölüm & Günlük & Maruziyet & Kiși & iş & Görev & KKD \\
& Çalş̧ma & Süresi & Sayısı/v & & & \\
& /Mola & & ardiya & & & \\
& Süresi & & Sayısı & & & \\
& & & & & & \\
\hline
\end{tabular}

\begin{tabular}{|c|c|c|c|c|c|c|}
\hline Şardon & $\begin{array}{c}9,5 \\
\text { saat/1 } \\
\text { saat }\end{array}$ & 8,5 saat & $\begin{array}{c}\text { kişi/ } \\
1 \\
\text { vardiya }\end{array}$ & $\begin{array}{c}\text { Şardon } \\
\text { makin } \\
\text { ası } \\
\text { operat } \\
\text { örü }\end{array}$ & $\begin{array}{c}\text { Fırçala } \\
\text { ma } \\
\text { Isşlemi } \\
\text { yapılm } \\
\text { aktadır }\end{array}$ & var \\
\hline Örme & $\begin{array}{c}9,5 \\
\text { saat/1 } \\
\text { saat }\end{array}$ & 8,5 saat & $\begin{array}{c}2 \text { kişi/ } \\
1 \\
\text { vardiya }\end{array}$ & $\begin{array}{c}\text { Örme } \\
\text { makin } \\
\text { ası } \\
\text { Operat } \\
\text { örü }\end{array}$ & $\begin{array}{l}\text { Battani } \\
\text { ye } \\
\text { kumaşı } \\
\text { örme } \\
\text { işlemi } \\
\text { yapılm } \\
\text { aktadır }\end{array}$ & var \\
\hline
\end{tabular}

Ölçüm sırasında; iş analizinde tespit edilen nominal gün şartlarının dışına çıkılmadığı gözlenmiştir. Görevler belirlenen süreler içinde gerçekleştirilmiştir ve tüm gürültü kaynakları tespit edilen sürelerde çalışmıştır.

Ölçüm sırasında; ölçüm sonuçlarının etkilenmesi muhtemel olayların tespiti için ölçüm süresi boyunca gelebilecek etkiler, puslu gürültü, ölçüm sonuçları ile ilgisi olmayan seslerin ölçüme etkisi olmadığı tespit edilmiştir.

Ölçüm İşlemi

a. Mikrofonun konumu

Dozimetrik cihazlarda mikrofon , çalıșanın omzundan yaklaşık $0,04 \mathrm{~m}$ yükseklikte ve maruziyet kaynağı tarafındaki kulağa en az 0,1 m uzaklığa konumlandırılmıştır.

b. Ölçüme metodu 
TS EN ISO 9612- akustik çalışma ortamındaki gürültünün tespiti ve değerlendirilmesi için prensipler

c. Ölçümde kullanılan ölçüm cihazları

Tablo 3. Ölçüm cihazları

\begin{tabular}{|c|c|c|c|c|}
\hline Bölüm & $\begin{array}{l}\text { Sicak } \\
\left({ }^{\circ} \mathrm{C}\right)\end{array}$ & $\begin{array}{l}\text { Basınç } \\
\text { (h Pa) }\end{array}$ & $\begin{array}{l}\text { Nem } \\
\text { (\%) }\end{array}$ & $\begin{array}{c}\text { Ruzgar } \\
\text { Hizl } \\
(\mathrm{m} / \mathrm{s}) \\
\end{array}$ \\
\hline $\begin{array}{l}\text { Şardon } \\
\text { Bölümü }\end{array}$ & 18,8 & 910,4 & 74 & 0,2 \\
\hline $\begin{array}{c}\text { Örme } \\
\text { Bölümü } \\
\end{array}$ & 18,7 & 910,2 & 74 & 0,1 \\
\hline Cihaz Adı & \multicolumn{2}{|c|}{ Marka } & Model & Tipi \\
\hline $\begin{array}{c}\text { Gürültü } \\
\text { Dozimetresi }\end{array}$ & \multicolumn{2}{|c|}{ EXTECH } & SL 355 & Tip 2 \\
\hline $\begin{array}{c}\text { Gürültü } \\
\text { Dozimetresi }\end{array}$ & \multicolumn{2}{|c|}{ EXTECH } & SL 355 & Tip 2 \\
\hline $\begin{array}{c}\text { Gürültü } \\
\text { kalibratörü }\end{array}$ & \multicolumn{2}{|c|}{ SVANTEK } & SV $30 \mathrm{~A}$ & TİP 1 \\
\hline $\begin{array}{c}\text { Basınç sıcaklık } \\
\text { ve nem ölçüm } \\
\text { Cihazı }\end{array}$ & \multicolumn{2}{|c|}{ TFA } & GAJA & - \\
\hline $\begin{array}{c}\text { Hava hızı } \\
\text { sıcaklık, Nem } \\
\text { ölçüm cihazı }\end{array}$ & \multicolumn{2}{|c|}{ TESTO } & $\begin{array}{c}\text { Testo } 410- \\
2\end{array}$ & \\
\hline
\end{tabular}

\section{Bulgular}

Tablo 4. Görev Tabanlı ölçüm stratejisine göre yapılan ölçüm sonuçları

\begin{tabular}{|c|c|c|c|c|c|}
\hline Bölüm & Görev & $\begin{array}{l}\text { Ölçüm } \\
\text { süresi }\end{array}$ & $\begin{array}{l}\text { Görev } \\
\text { süresi }\end{array}$ & (Lex, 8h, m) & $\begin{array}{c}\text { Kişisel } \\
\text { maruziyet } \\
\text { (Lex, 8h) } \\
\text { dB A }\end{array}$ \\
\hline \multirow[t]{6}{*}{ Şardon } & \multirow{6}{*}{$\begin{array}{l}\text { Fırçalam } \\
\text { a işlemi } \\
\text { yapılmak } \\
\text { tadır }\end{array}$} & \multirow[t]{6}{*}{15 dakika } & \multirow{6}{*}{$\begin{array}{c}8,5 \\
\text { saat }\end{array}$} & 89,3 & 89,6 \\
\hline & & & & 89,0 & 89,3 \\
\hline & & & & 89,5 & 89,8 \\
\hline & & & & 88,9 & 89,2 \\
\hline & & & & 89,2 & 89,5 \\
\hline & & & & 89,5 & 89,8 \\
\hline \multirow[t]{6}{*}{ Örme } & \multirow{6}{*}{$\begin{array}{c}\text { Battaniye } \\
\text { kumaşı } \\
\text { örme } \\
\text { işlemi } \\
\text { yapılmak } \\
\text { tadır. }\end{array}$} & \multirow[t]{6}{*}{15 dakika } & \multirow{6}{*}{$\begin{array}{c}8,5 \\
\text { saat }\end{array}$} & 82,0 & 82,3 \\
\hline & & & & 82,3 & 82,6 \\
\hline & & & & 82,1 & 82,4 \\
\hline & & & & 82,5 & 82,8 \\
\hline & & & & 81,9 & 82,2 \\
\hline & & & & 82,7 & 83,0 \\
\hline
\end{tabular}

Çalışmada, gürültü değerlerinin tespit edildiği örme ve şardon makinalarının kullanıldığı işletme koşullarında elde edilen ölçüm değerleri incelendiğinde, şardon makinası tarafından ortama yayılan görevin kişisel maruziyet katkısı ve kişisel maruziyet değerleri örme makinalarına göre daha yüksektir. Ölçüm yapılan çalışma alanlanında gürültü düzeyindeki farklılığın, şardon makinalarının örme makinasına göre işlevsel yapısı farklılığından kaynaklanmaktadır.Ölçüm belirsizliği ile birlikte değerlendirildiğinde TS EN ISO 9612 standardına uygun olarak hesaplanan ölçüm belirsizliği Şardon bölümü için $\pm 3 \mathrm{~dB}$ dir. TS EN ISO 9612 standardına uygun olarak hesaplanan ölçüm belirsizliği örme bölümü $\pm 3 \mathrm{~dB}$ dir.

Tablo 5. Ölçüm şartları

Tablo 6. Ölçüm öncesi ve sonrası yapılan doğrulama

\begin{tabular}{|l|l|l|l|}
\hline & Kayıt No & $\begin{array}{l}\text { Gerçek } \\
\text { değer (dB) }\end{array}$ & $\begin{array}{l}\text { Okunan } \\
\text { değer (dB) }\end{array}$ \\
\hline Başlangıç & Run 1 & 114,0 & 113,7 \\
\hline Bitiş & Run5 & 114,0 & 113,8 \\
\hline
\end{tabular}

\section{Tartışma ve Sonuç}

Çalışanın sağlığını negatif yönde etkileyen ve düzeltilmesi mümkün olmayan sonuçlara sebep olan gürültünün kontrol altına alınması gerektiği bir gerçektir. Çalışan sağlığı üzerinde etkileri artan gürültü konusunda çalışanların, özellikle genç işçilerin bilinçlendirilmesi gerekmektedir. İşyeri ortamından kaynaklanan problemlerin tümünde çözüm eğitim ile sağlanacaktır.

Gürültünün ișçi üzerindeki fizyolojik etkileri gürültüden etkilenme miktarına bağlı olarak değişmektedir. Bunlar, gürültüye bağlı kalıcı işitme problemleri, solunum rahatsızlıkları, tansiyon, kalp hastalıklarıdır. Gürültünün çalışan bireye olumsuz fizyolojik etkileri ve psikolojik etkileri de ortaya çlkmaktadır. Bunların arasında en çok olanı, maruz kalınan gürültünün oranı ile direkt olarak iliş̧ilendirilebilen, gürültülü ortamlarda bulunan işçilerde görülen gürültüye bağlı verim düşüklüğüdür. Gürültünün işçi sağlığı üzerindeki negatif etkileri arasında çalışanları etkileyen sağlık sorunu; işçiler arasında oldukça çok görülmesi sebebi ile, gürültüye bağlı kalıcı işitme sorunlarıdır. Söz konusu işitme kayıpları çalışanın yaşam kalitesini önemli ölçüde artıracaktır.. Gürültü etkisi ile artan işitme kayıplarının ileri seviyelerde ise konuşmayı etkilenmekte, ve işyerindeki çalışanlar arası iletişimi negatif yönde durumlar ortaya çıkmaktadır.

Battaniye işletmesindeki yüksek gürültü düzeyinde çalışılması, sağlı̆̆ı olumsuz yönde etkilemektedir. Bu çalışmada örme ve şardon makinasının ortama yaydığ gürültü düzeyi değerleri tespit edilmiştir.

Şardon makinalarının yaydı̆̆ı görevin kişisel maruziyet katkısı değerleri 88,9 ile 89,5 dB arasında değişirken, kişisel maruziyet 89,2 ile 89,8 dB arasındadır. 
Örme makinalarının yaydığı görevin kişisel maruziyet katkısı değerleri 81,9 ile 82,7 dB arasında değişirken, kişisel maruziyet 82,2 ile $83 \mathrm{~dB}$ arasındadır.

İnsan sağlığına doğrudan etkili olan gürültünün oluştuğu iş yerlerindeki işçiler tarafından, gürültünün etkisini azaltan kulaklık vb. kişisel koruyucular kullanılmalıdır.. Örme ve Şardon makinasının oluşturduğu gürültüyü çevreye yayılmasını önlemede birinci öncelik toplu koruma yöntemi olan kaynağında korumadır. Kișisel önlemlerden önce kaynağındaki gürültü düzeylerini azaltılması işçilerin gürültüden etkin biçimde korunması gerekmektedir. İşletmelerde gürültünün bir dizayn ölçütü olarak işyerinin yapım aşamasında göz önünde tutulmalı; iş ekipmanlarının yerleşim aşamasında gürültünün minimuma indirecek düzenlemeler yapılmalıdır.

\section{Kaynakça}

[1] Özgüven, N. 1986. Endüstriyel Gürültünün Kontrolü, OTÜ, TMMOB Makina Mühendisleri Odası, Yayın No: 118, Ankara.

[2] İlgürel ,N., Sözen, M., 2005. Sanayi İşletmelerinde Gürültünün Nesnel, Öznel ve Yönetmelikler Bağlamında İncelenmesi, Cilt 1, sayı 1 , MMGARON YTÜ Mim. Fak. E-Dergsi

[3] Ege, F., Sümer, K.,Sabancu, A., 2003. Tekstil işletmelerinde Gürültü Düzeyi ve etkileri, Türk tabipler Birliği Mesleki sağlık ve Güvenlik Dergisi,

[4] Nacar Koçer, C., Uslu, G., Işılk, H. ve Hanay, Ö., 2007; "Elazığ'da Gürültü Üzerine Endüstrinin Etkisi”, 7. Ulusal Çevre Mühendisliği Kongresi, 24-27 Ekim, İzmir.

[5] Atmaca, E. ve Peker, İ., 1999; "Sivas ili Araç Gürültüsü", Ekoloji Çevre Dergisi, Cilt 8, Sayı 30, s.3-8.

[6] Yılmaz, H. ve Özer S., 1997; “Gürültünün Peyzaj Yönünden Değerlendirilmesi ve Çözümü" Ziraat Fakültesi Dergisi, Cilt 28, Sayı 3, s.515-531.

[7] Funda, Y.O., 2012; "Gürültü Maruziyetin İşitme Üzerindeki Etkisini, Sigara Kullanımı ve Kotinin ile İlișkisinin İncelenmesi”, Abant İzzet Baysal Üniversitesi Uzmanlık Tezi, s.103.

[8] Maschke C., Rupp T. ve Hecht K., 2000; "Stresörlerin biyokimyasal reaksiyonlar üzerindeki etkisi - gürültülü mevcut bilimsel bulguların bir incelemesi”, Int J Hyg Environ Health, Cilt 203, s.45-53. 